\title{
Weight and Diameter Estimation Using Image Processing and Machine Learning Techniques on Apple Images
}

\author{
Onur CÖMERT $^{1 *}$, Mahmut HEKIM ${ }^{2}$, Kemal ADEM $^{3}$ \\ ${ }^{1}$ Gaziosmanpaşa University, Faculty of Engineering, Mechatronics Engineering \\ ${ }^{2}$ Gaziosmanpaşa University, Faculty of Engineering, Electrical and Electronics Engineering \\ ${ }^{3}$ Gaziosmanpaşa University, Department of Informatics
}

Başvuru/Received: 08/10/2017

Kabul/Accepted: 01/12/2017

Son Versiyon/Final Version: 26/12/2017

\begin{abstract}
Classification of table fruits according to size is traditionally hand made. But human factors are the cause of faulty classifications. Automatically performing this process with the machines is important in terms of speeding up the process, reducing costs, and minimizing errors. In this study, weight and diameter estimations were made on "Starking" type apples using image processing techniques. Firstly 50 photographs were taken with NIR camera and 830nm long pass filter. Afterwards, edge detection algorithms and morphological operations were performed on the images to obtain the boundaries of the images. Diameter and area information obtained from the binary image were used as attributes. These attributes were given as input to Linear Regression method and estimated. As a result, $93 \%$ of the diameters of the apples and $96.5 \%$ of the weights could be estimated.
\end{abstract}

\section{Key Words}

"Starking Apple, Image Processing, Linear Regression" 


\section{INTRODUCTION}

According to FAO (2010), Turkey, which has come after China and the USA in the production of apples, tends to move this place to the upper level every passing day. Apple is one of the most fruit produced in the world after bananas, grapes and oranges. In Turkey, fruit is the most produced fruit after grape (Anonymous,2016).

Automation systems are increasingly important in the food industry based on agricultural products. In this sector, the classification of vegetables and fruits according to their qualities and specifications is usually done manually by quality control workers. However, this method does not provide a complete standard and sometimes misclassifications can be made. For this reason, the automatic determination of the size of the apples is important in terms of speeding up the classification process and making it cheaper (Kondo, 2010).

In this study, the dimensions and weights of the apples were automatically estimated using image processing and machine learning methods on apple images transmitted digitally through a camera, thus facilitating classification.

\section{LITERATURE}

Looking at the scientific studies on image processing and machine learning methods used on fruits and vegetables, it was generally seen that industrial type cameras with CCD (Er et al., 2013), (Sofu et al., 2013), (Tonguç \& Yakut, 2009), (Xiaobo et al., 2007) or Monochrome (Unay, 2005), (Unay \& Gosselin, 2005) technology are used.

In some studies have used usually between 450nm and 1000nm band-pass NIR (Near Infrared) filters. A large number of images were taken with these filters and analyzed on these images. This makes it easier to foreground the desired region in the image (Unay, 2005), (Unay \& Gosselin, 2005), (Unay \& Gosselin, 2005).

Conventional methods were preferred for image processing and feature extraction stages. Filtering (Er et al., 2013) and color space transformations (Er et al., 2013), (Tonguç \& Yakut, 2009), (Xiaobo et al., 2007) in the preprocessing phase, thresholding (Er et al., 2013), (Unay, 2005), (Unay \& Gosselin, 2005) in the segmentation phase, and statistical and graphical properties (Unay, 2005), (Unay \& Gosselin, 2005) in the feature extraction phase were used.

Support Vector Machine and Artificial Neural Networks (Unay, 2005), (Unay \& Gosselin, 2005), (Unay \& Gosselin, 2005), (Xiaobo et al., 2007) as classification methods and Linear Regression and Decision Trees (Er et al., 2013) as estimation methods were used.

\section{MATERIAL AND METHOD}

In this section, firstly, how to get the images used in working is explained. Then, the image processing techniques used on the images are explained according to the order of application. Finally, the results obtained by the estimation process are given.

The process flow diagram showing the sequence of operations performed in Figure 1 is shown. 


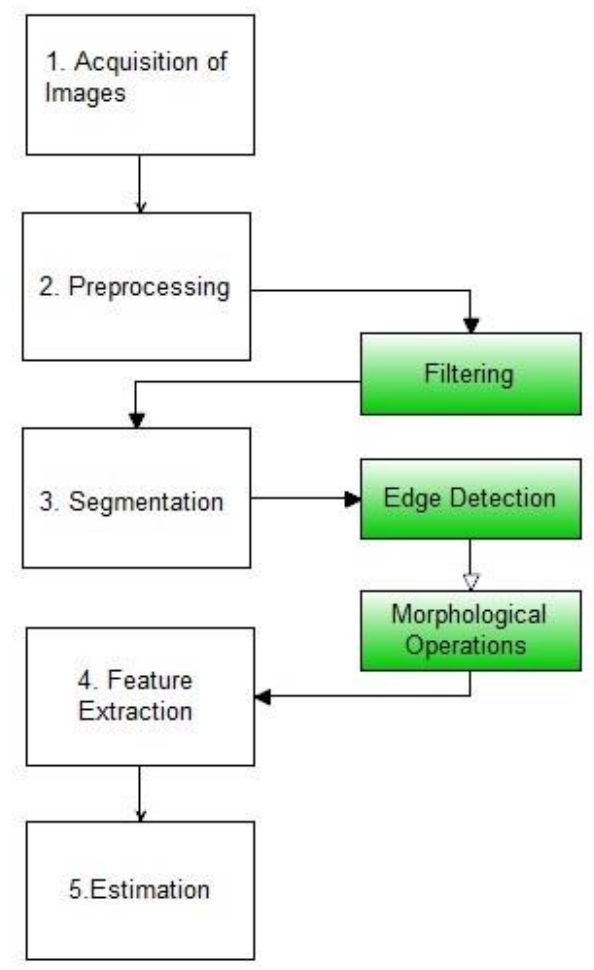

Figure 1: Process flow diagram

As you can see in Figure 1, there are five main groups of operations. These operations are explained in detail in the ongoing subheadings.

\subsection{Obtaining Data}

The images used in the study were obtained by means of a pre-established image acquisition platform. The platform was designed to be able to transmit light from outside and contains artificial lighting elements (Tungsten Halogen Lamps). Within the platform, there are NIR camera, lens and longpass filter for image acquisition. Since the camera can transfer data directly to the computer via Ethernet, no other intermediate card is needed. The NIR camera features used are given in Table 1.

Table 1: Teledyne DALSA Genie Nano NIR features

\begin{tabular}{|c|c|}
\hline Model Type & Mono/NIR \\
\hline Shutter & Global \\
\hline Sensor Type & CMOS \\
\hline Sensor Model & On-Semi Python 2000 \\
\hline Active Resolution & $1900 x 1200 \mathrm{dpi}$ \\
\hline Max frame rate & 50 \\
\hline Image Size & $2.2 \mathrm{Megapixel}$ \\
\hline Sensor Format & $2 / 3$ " \\
\hline Pixel Size & $4.8 \times 4.8 \mu \mathrm{m}$ \\
\hline Data Format & 8 or 10bit Mono \\
\hline Connection Type & Gigabit Ethernet \\
& (1000Mbit/s) \\
\hline Lens Mount & C-mount \\
\hline Exposure Control & Programmable \\
\hline
\end{tabular}


Table 2. Fujinon HF16HA-1B features

\begin{tabular}{|c|c|}
\hline Mount Type & C-mount \\
\hline Focus size & $2 / 3^{\prime \prime}, 1 / 2^{\prime}, 1 / 3^{\prime}$ \\
\hline Min. Focus distance & $16 \mathrm{~mm}$ \\
\hline Iris interval & F1.4 F16 \\
\hline Iris & Manually \\
\hline Focus & Manually \\
\hline Max angle of view & $\begin{array}{c}17^{\circ} 04^{\prime} \text { horizantal, } \\
12^{\circ} 50^{\prime} \text { vertical }\end{array}$ \\
\hline Min object distance & $10 \mathrm{~cm}$ \\
\hline Macro & No \\
\hline Dimensions & $29.5 \times 29.5 \times 29.5 \mathrm{~mm}$ \\
\hline Weight & $45 \mathrm{gr}$ \\
\hline \multicolumn{2}{|c}{}
\end{tabular}

The lens type determined by considering the scanning area and the object distance is Fujinon brand HF16HA-1B model. The lens properties are given in Table 2.

A computer with a 4-core processor with a clock speed of $2.6 \mathrm{GHz}$ was used to record and process images. The image acquisition system used in Figure 2 is shown.

As shown in Figure 2, a matte black material was preferred for the floor on which the apples are to be placed. This fabric material used on the roof does not reflect the infrared rays, so the background is seen as black. The reason for this is to make it easier to distinguish the hand from the background.

Mirrors were placed on the inner walls of the platform to distribute the light evenly over the entire apple surface and to prevent shading.

A $830 \mathrm{~nm}$ Long-pass filter was used in front of the lens. Thanks to this filter, the beams in the visible region can not reach the camera, so a clearer image is obtained.

A $830 \mathrm{~nm}$ Long-pass filter was used in front of the lens. Thanks to this filter, the beams in the visible region cannot reach the camera, so a clearer image is obtained. Tungsten Halogen lamps have a very wide wavelength range (Anonymous,2017). Therefore, Tungsten Halogen lamps have been chosen as the lighting element for the wavelength range to be suitable for this filter. There are also white leds on the platform, but these beams did not used with NIR camera because they do not appear in the infrared region. Leds have a narrower wavelength range than Halogen Lambs, but Leds have better image performance for lighting purposes (Anonymous,2012) Therefore, LEDs was used with color camera.

The Matlab program was installed on the computer to receive and process the image data. 50 Starking type apples were used to create image data. The apples were randomly selected from an ordinary grocery store. Images were taken from six different directions of the hand and a total of 300 images were obtained. Then, these apples were weighed with a precision electronic scale and their diameters measured with a caliper. These values were recorded and actual diameter and weight data were created. The following table shows the measured diameter and weight values of the apples.

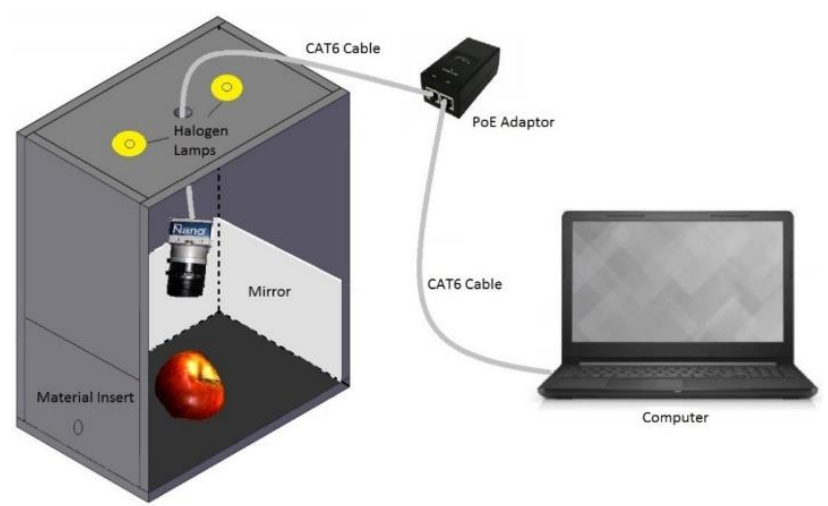

Figure 2: The image processing system 
Table 3: Measured diameter and weight values of apples

\begin{tabular}{|c|c|c|c|c|c|}
\hline No & $\begin{array}{c}\text { Weight } \\
(\text { gr })\end{array}$ & $\operatorname{Dia}(\mathrm{mm})$ & No & Weight(gr) & $\operatorname{Dia}(\mathrm{mm})$ \\
\hline 1 & 143 & 71 & 26 & 231 & 85 \\
\hline 2 & 125 & 69 & 27 & 166 & 73 \\
\hline 3 & 124 & 65 & 28 & 182 & 79 \\
\hline 4 & 126 & 71 & 29 & 152 & 73 \\
\hline 5 & 124 & 65 & 30 & 202 & 80 \\
\hline 6 & 151 & 72 & 31 & 160 & 73 \\
\hline 7 & 134 & 67 & 32 & 184 & 75 \\
\hline 8 & 115 & 64 & 33 & 167 & 72 \\
\hline 9 & 156 & 72 & 34 & 190 & 77 \\
\hline 10 & 114 & 64 & 35 & 129 & 68 \\
\hline 11 & 117 & 65 & 36 & 196 & 75 \\
\hline 12 & 136 & 67 & 37 & 155 & 74 \\
\hline 13 & 143 & 71 & 38 & 154 & 72 \\
\hline 14 & 117 & 67 & 39 & 181 & 78 \\
\hline 15 & 141 & 71 & 40 & 183 & 76 \\
\hline 16 & 132 & 72 & 41 & 110 & 68 \\
\hline 17 & 126 & 67 & 42 & 130 & 68 \\
\hline 18 & 119 & 66 & 43 & 135 & 69 \\
\hline 19 & 131 & 68 & 44 & 146 & 70 \\
\hline 20 & 169 & 73 & 45 & 137 & 69 \\
\hline 21 & 218 & 81 & 46 & 133 & 70 \\
\hline 22 & 224 & 80 & 47 & 127 & 66 \\
\hline 23 & 189 & 77 & 48 & 170 & 75 \\
\hline 24 & 184 & 77 & 49 & 98 & 63 \\
\hline 25 & 136 & 73 & 50 & 123 & 67 \\
\hline
\end{tabular}

\subsection{Preprocessing}

As is known, preprocessing is a process or process group performed to remove unwanted portions of an image. In the preprocessing phase of the paper, a cropping at fixed width was first made in the image. On this count, parts without apples have been removed from the image. The second process is to soften the image to provide a better segmentation. Figure 3 shows how cropping is done.
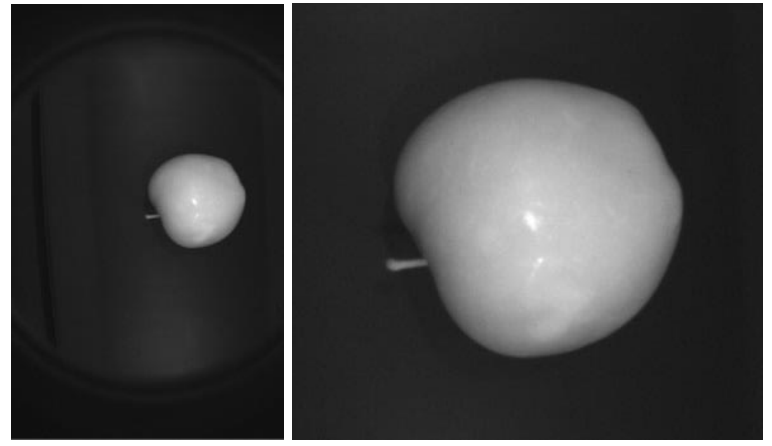

Figure 3: The preprocessing stage

Figure 3 shows two images. The image on the left shows the original image transferred from the image acquisition system to the computer, while the image on the right shows the image clipped on the computer.

\subsection{Segmentation}

Segmentation is the process of separating the part or parts of interest in the image from the background. In this phase, the image is usually converted to binary by specifying a manual threshold value.

In this work, it was aimed to separate the apple object in the image from the background. For this, a more dynamic method was preferred rather than a fixed threshold value. First, boundaries of apple in the image were determined by applying the Prewitt edge extraction algorithm. On this obtained binary image, closing, filling and opening processes were applied in order to obtain a binary image in which area covered by apple object is white and the other parts are black. It is seen that these operations are applied as below. 

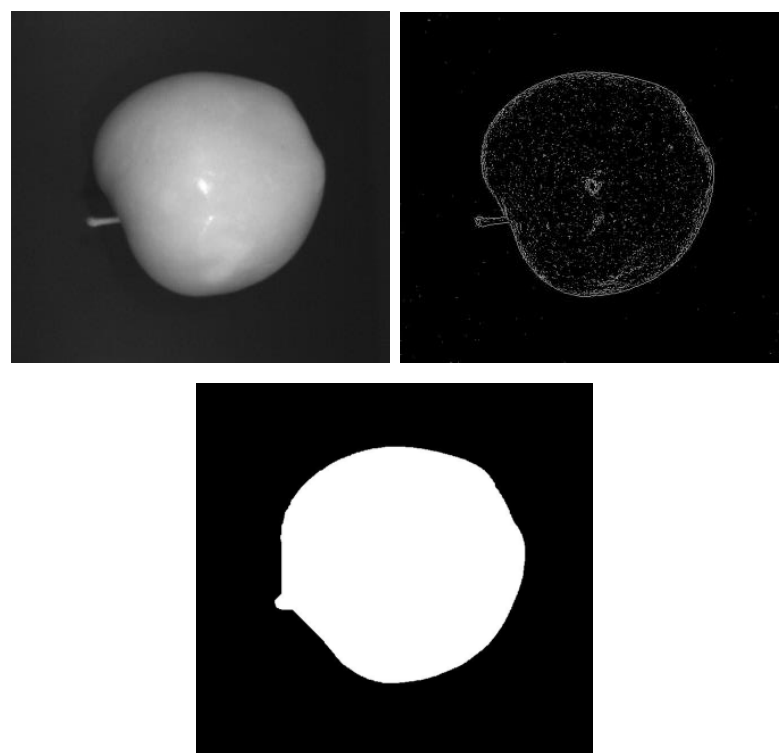

Figure 4: The segmentation stage

In Figure 4, the second image is the binary image formed after the edge detection process. The third image is an image in which the closing, filling and opening process has been applied and the background is completely separated from the apple. This image will be used for feature extraction during forecasting.

\subsection{Feature Extraction}

In the feature extraction phase, the goal is to obtain the sequence of values that will be input into the machine learning methods. These properties may be statistical properties of the objects in the image, as well as shape features such as the area and size of the objects.

Since our aim in our study is to estimate the weight and the diameter of the apple, the area and the diameter of the object in pixels are determined. In order to obtain the diameter information of the apple, the environment was first determined. Then, its diameter was obtained considering the circular structure of the apple. The figure below shows the diameter and area information of the apple.

Figure 5 shows the green pixel area and diameter information on the apple.

In Table 4, the obtained area and diameter information are presented in pixels.
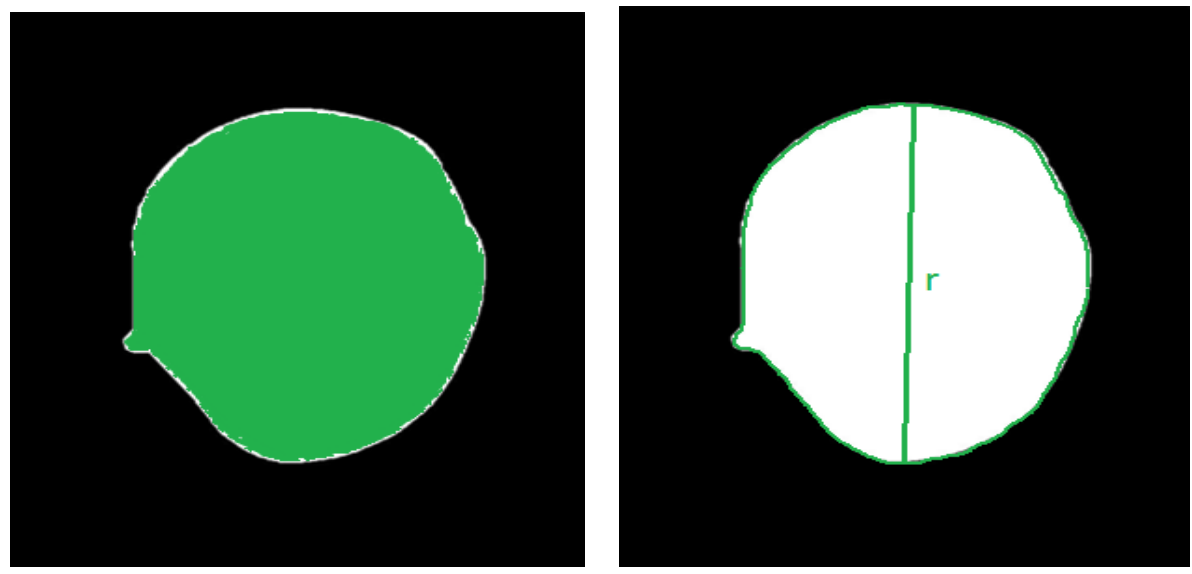

Figure 5: The feature extraction stage 
Table 4: Estimated area and diameter values of apples

\begin{tabular}{|c|c|c|c|c|c|}
\hline No & Area(pixel) & Dia(pixel) & No & Area(pixel) & $\overline{D i a(p i x e l)}$ \\
\hline 1 & 140280 & 388 & 26 & 206409 & 543 \\
\hline 2 & 123991 & 363 & 27 & 170761 & 444 \\
\hline 3 & 126773 & 363 & 28 & 173632 & 452 \\
\hline 4 & 125506 & 390 & 29 & 145991 & 405 \\
\hline 5 & 121553 & 356 & 30 & 186005 & 568 \\
\hline 6 & 138326 & 405 & 31 & 158168 & 443 \\
\hline 7 & 130484 & 368 & 32 & 166489 & 485 \\
\hline 8 & 118524 & 358 & 33 & 131539 & 439 \\
\hline 9 & 138467 & 408 & 34 & 160422 & 505 \\
\hline 10 & 116143 & 354 & 35 & 134015 & 384 \\
\hline 11 & 122808 & 359 & 36 & 143398 & 497 \\
\hline 12 & 133099 & 372 & 37 & 142392 & 435 \\
\hline 13 & 134406 & 393 & 38 & 157447 & 414 \\
\hline 14 & 119072 & 354 & 39 & 159849 & 477 \\
\hline 15 & 136068 & 377 & 40 & 159111 & 484 \\
\hline 16 & 132257 & 370 & 41 & 117214 & 354 \\
\hline 17 & 128564 & 367 & 42 & 123008 & 408 \\
\hline 18 & 118435 & 350 & 43 & 130398 & 382 \\
\hline 19 & 130089 & 368 & 44 & 141205 & 401 \\
\hline 20 & 153238 & 449 & 45 & 130797 & 418 \\
\hline 21 & 211526 & 533 & 46 & 136551 & 376 \\
\hline 22 & 185908 & 536 & 47 & 131009 & 369 \\
\hline 23 & 193931 & 485 & 48 & 172087 & 490 \\
\hline 24 & 172420 & 527 & 49 & 106462 & 333 \\
\hline 25 & 139245 & 385 & 50 & 130753 & 375 \\
\hline
\end{tabular}

As shown in Table 4, area and diameter values are directly proportional to each other. This shows the correctness of the calculated values. These values will be used for estimation at the next stage.

\subsection{Estimation}

Linear Regression method was used to estimate the diameters and weights of the apples. This method was preferred because data is linear and it is a rapid method.

\section{Linear Regression}

Regression is the simplest method for classifying and predicting (making the right adjustments) on a given dataset. There are two approaches for regression: linear and nonlinear. The linear regression approach assumes that there is a specific error between the weighted sum of the input variables and the output variable. In this case there is a linear connection between the input variables and the output. The multiple linear regression equation used for input data with multiple properties is shown in Equation-1.

$$
Y=W_{0}+\sum_{j=1}^{N} W_{j} X_{j}+E
$$

$\mathrm{W}_{\mathrm{j}}$ in Equation 1 represents the weight values, $\mathrm{X}_{\mathrm{j}}$ is the feature vector of the data, $\mathrm{N}$ is the total number of features in the data, $\mathrm{E}$ is the error, and $\mathrm{Y}$ is the target variable. The important thing here is to find the $\mathrm{W}_{\mathrm{j}}$ values. The most common method for this is the least squares method (Chapra \& Canale, 2003). The least squares method is based on finding the equation coefficients that minimize the sum of squared errors. The main principle of this method is based on the smallest of the Mean Squared Error (MSE) expressed in Equation 2 below.

$$
\operatorname{MSE}=\frac{1}{\mathrm{~N}} \sum_{\mathrm{i}=1}^{\mathrm{N}}\left(\mathrm{d}_{\mathrm{i}}-\overline{\mathrm{d}_{1}}\right)^{2}
$$

$$
\mathrm{RMSE}=\sqrt{\mathrm{MSE}}
$$

$\mathrm{d}_{\mathrm{i}}-\overline{\mathrm{d}}_{1}$ in Equation 2 indicates the distance (error) between each target variable and the correct equation to be calculated. Root Mean Square Error (RMSE) in Equation-3 is used to determine the error rate between the measured values and the estimates. The approach of the RMSE value to zero means that the estimation capability of the system is increased (Singh et al., 2009).

A 10-part cross validation has been applied to test the classification success. As a result, the diameters of the apples $93 \%$ and the weights $96.5 \%$ could be correctly estimated. 


\section{RESULTS}

In this study, it was aimed to estimate the diameter and weight values of the Starking apples which are the most grown apple varieties in Turkey by image processing methods. Through a generated image acquisition system, features were extracted from images taken from 6 different directions of 50 apples. These properties were used as an input to the Linear Regression method for estimating the diameters and weights of the apples and as a result, the diameters of the apples $93 \%$ and their weights $96.5 \%$ were correctly estimated.

\section{ACKNOWLEDGMENT}

This study was supported by Gaziosmanpaşa University Institute of Natural and Applied Sciences as BAP project (2016/28).

\section{REFERENCES}

Anonymous, "Light-emitting diode". Wikipedia, https://en.wikipedia.org/wiki/Light-emitting_diode\#cite_note-56 (24.04.2017), 2017a.

Anonymous, “Halogen Lamp". Wikipedia, https://en.wikipedia.org/wiki/Halogen_lamp (24.04.2017), 2017b.

Anonymous, "Dünya meyve suyu sektörüne bakış". MEYED/Meyve Suyu Endüstrisi Derneği, http://www.meyed.org.tr/userfiles/file/sektor_istatistikleri/dunya_meyve_suyu_sektorune_bakis_akdag.pdf (08.04.2016), 2016.

Anonymous, "All in 1 LED Lighting Solutions Guide. PhilipsLumileds", https://web.archive.org/web/20130314111003/http://www.philipslumileds.com/uploads/221/PG01-pdf (24.04.2017). 2012.

Chapra, S. C. and Canale, R. P. "Yazılım Ve Programlama Uygulamalarıyla Mühendisler İçin Sayısal Yöntemler”. Literatür Yayıncilik, ISBN: 975-8431-83-8. 2003.

Er, O., Cetişli, B., Sofu, M. M. and Kayacan, M. C., "Gerçek Zamanlı Otomatik Elma Tasnifleme". Süleyman Demirel Üniversitesi Fen Bilimleri Enstitüsü Dergisi, 17(2), 31-38. 2013.

Kondo, N., "Automation on fruit and vegetable grading system and food traceability". Trends in Food Science Technology, 21, (145-152). 2010.

Singh, K.P., Basant, A., Malik, A. and Jain, G. "Artificial neural network modeling of the river water quality-A case study", Ecological Modelling, 220(6), 888-895. 2009.

Sofu, M. M., Er, O., Kayacan, M. C. and Cetişli, B., "Elmaların Görüntü İşleme Yöntemi ile Sınıflandırılması ve Leke Tespiti”, Gıda Teknolojileri Elektronik Dergisi, 8(1), 12-25. 2013.

Tonguç, G. and Yakut, A. K., "Fruit grading using digital image processing". Tarım Makinaları Bilimi Dergisi, 5(1), 93-101. 2009.

Unay, D., “A stem-and/calyx recognition system based on pattern recognition for 'jonagold' apples". Tech. Rep., TCTS Labs., Faculte Poly- technique de Mons. 2005.

Unay, D. and Gosselin, B., “Artifical Neural Network-Based Segmentation and Apple Grading”. IEEE International Conference on Image Processing, 2, 630-633. 2005.

Unay, D. and Gosselin, B., “Thresholding-Based Segmentation And Apple Grading By Machine Vision”. Tech. Rep., TCTS Labs., Faculte Poly- technique de Mons. 2005.

Xiaobo, Z., Jiewen, Z. and Yanxiao, L., “Apple color grading based on organization feature parameters". Pattern Recognition Letters, 28, 2046-2053. 2007. 